\title{
GRAPH THEORY IN NETWORK ANALYSIS
}

\author{
J.A. BARNES \\ University of Cambridge * \\ Frank HARARY \\ University of Michigan **
}

For many centuries ideas now embodied in graph theory have been implicit in lay discussions of networks. The explicit linking of graph theory and network analysis began only in 1953 and has been rediscovered many times since. Analysts have taken from graph theory mainly concepts and terminology; its theorems, though potentially valuable for the analysis of real data, are generally neglected. Network analysts thus make too little use of the theory of graphs. Some instances of the use of theorems for network analysis are noted.

Boissevain (1979: 394) complains that "if anthropologists and sociologists continue to view network analysis as a special field of inquiry, and if those who use it continue to encourage this view, it will rapidly become overly technical and its results progressively trivial". Boissevain is not alone in making this criticism. A recent conference paper was entitled "The unfulfilled promise of network analysis" (Allan 1980) and even Bott (1971:323), whose early work on married couples inspired many subsequent studies of social networks, warns against the dangers of "network-ology - getting lost in classification exercises for the fun of it". There are many critics who point scornfully at the mismatch they see between the claims and achievements of network analysts. In this short paper we do not discuss these claims (we believe that network analysts have usually been considerably more modest than their critics allege), nor do we undertake yet another survey of achievements in network analysis, a task that becomes more formidable every year.

* University of Cambridge, Cambridge, U.K.

** University of Michigan. Ann Arbor, MI 48104, U.S.A. 
Instead, we argue that one of the rcasons why many of the results of network analysis are trivial is, contrary to Boissevain's view, that they are insufficiently technical, in that they fail to utilize the analytic power latent in graph theory.

The closeness of the link between network analysis and graph theory is widely recognized, but the nature of the link is seldom discussed. Graph theory, like all other branches of mathematics, consists of a set of interconnected tautologies. The lattice of their interconnections provides us, at least in retrospect, with an unproblematic outline for a history of the theory (Harary 1969, 1973). Network analysis has no analogous lattice of propositional interconnections and its history is contestable. Although it can now be defined ostensively by pointing to the pages of Social Networks and similar journals, its institutionalization as an accepted specialism is only recent, and no account of its origins has yet achieved the status of the orthodox myth. Leinhardt (1977) gave his collection of articles on social networks the subtitle "a developing paradigm", and his choice of papers constitutes an attempt to define the origin and course of that development. He chose Moreno (1934) and Heider (1946), while Heider himself (1979:16) derives his own work on balance theory from Spinoza's Ethics, published in 1677. Mitchell (1969) looks back to Radcliffe-Brown (1940), while Mayer (1966) cites Chapple and Coon (1942). Whitten and Wolfe (1973) invoke Roethlisberger and Dickson (1939) and Warner and Lunt (1941). What now seems interesting about this pedigree construction is that none of these candidate pioneers made use of graph theory. Indeed, we may confidently assume that they were unaware of its existence, at least at the time they wrote their classic works.

The language of graphs can be uscd to model many notions that were current long before graph theory was born. The most notable of these was the mnemonic of places and images recommended for orators in the first century B.C. by Cicero and others (Yates 1966: 17-41) and still in use not only in industrialized societies but also among some contemporary pre-literate communities (Harwood 1976; Hage 1978). The mnemonic is equivalent to specifying a walk, or in Cicero's case a path, containing all the points of a tree (Harary 1969:13). Graph theory took shape only slowly, with a gap of two hundred years between Euler's founding paper of 1736 and König's definitive monograph of 1936. In the interim Kirchhoff (1847) and Cayley (1857) developed theorems in graph theory and applied them to electrical circuits and chemical isomers respectively. 
The first indisputable application of graph theory to network analysis did not come until 1953, with Harary and Norman's short monograph. Cartwright (1953) attaches the work to a line of descent leading from Kurt Lewin (1936) and Clark Hull (1940) through Bavelas (1948). With the benefit of hindsight we would argue that this union of graph theory and network analysis was one instance, distinguished by its comparative subsequent success, of attempts to express, in relatively formal terms, customary social arrangements and configurations of actual social bonds. Another such attempt was made, probably prematurely and certainly with less success, by Chapple in his contribution to the textbook written with Coon, in which he tried to blend two styles of analysis, the counting and measuring associated with his interaction chronograph (Chapple 1940) and the identification of distinctive unquantified patterns, exemplified in the cryptically designated "set" (Chapple and Coon 1942: 285). Whereas the former derived from the statistical tradition in psychology, the latter has strong similarities with Lewin's work. The latter tradition, which has the closer ties to graph theory, is also to be seen in Armstrong's remarkable monograph Rossel Island (1928), which contains not only the notion of "tribal distance", equivalent to graph theoretic distance, but also a "General theory of the classifactory system of relationships", in which he presents a typology of prescriptive marriage class systems, most of them hypothetical. This line of thinking was taken further by Layard in an impressive discussion, with 3-dimensional diagrams, of hypothetical 12-class systems in which he acknowledges help from Gregory Bateson (Layard 1942: 113). In retrospect it is interesting, particularly in Bateson's case, that these anthropologists appear to have had no contact with mathematicians on this aspect of their work.

Most social scientists at that time probably identified mathematics with statistics, and in rejecting a statistical mode of analysis they assumed that mathematics had no help to offer them. Thus Cartwright (1953: iii) contrasts old-style help for social scientists from statisticians with new-style help from graph theorists, topologists and the like. Similarly Lévi-Strauss (1954: 585-586) contrasts quantitative mathematics with what he calls qualitative mathematics, and describes his surprise at discovering in André Weil a new type of mathematician who, unlike the statisticians, had something relevant to say in the analysis of structures. Weil's (1949) contribution to Lévi-Strauss' magnum opus was perhaps the first explicit attempt to apply combinatorics 
to the analysis of social structure; it was introduced to Anglophone readers by White (1963:159-172).

There is at least one other line of descent that leads to network analysis and graph theory, or rather a line in which both partners in this union have, in embryonic form, already been united for hundreds of years. Genealogical diagrams are diagrams of graphs, for they contain individual persons as nodes, linked by relations of affinity. parenthood and siblingship. Diagrams of this kind have heen in practical use in many parts of the world, and oral descriptions of these configurations of relations have been with us for thousands of years (Barnes 1967: 103). Yet though the social networks expressed in genealogies have been diligently and contentiously analysed through the ages. until Morgan (1870) there was very little that could be called "theory" in this analysis. Once graph theory was seen to have relevance for the analysis of social networks, genealogical diagrams, as graphs, became an obvious site for applying this theory. The contrast between the discussion of graphs in isolation from graph theory, typified by the work of Armstrong, Layard and Bateson, and the application of theory to these graphs typical of present-day analysis, is shown by two analyses of the "atom of kinship". Lévi-Strauss (1945: 48, 50; 1953: 5: cf. 1963: 46, 48, 72). who coined this term to denote the configuration of a woman, her brother, her husband and their son, discusses their interrelations with half an cye on properties of symmetry and asymmetry and with half an eve on the incest taboo. Flament (1963: 125-126) uses the theory of balance in signed graphs to predict the empirically possible configurations of signed relationships in the Levi-Strauss "atom of kinship". To do this, he makes assumptions about the signs of the two relations in the configuration that Lévi-Strauss ignored Our understanding of the "atom" is thereby enhanced. The present paper is presented in the hope that it may elicit further applications of theory to data that will be equally rewarding.

Granovetter (1979:501), surveying the literature on network analysis, asks "Where is the theoretical underpinning for all these models and analyses?" Part of the answer can be easily found in what are often referred to disparagingly but unproblematically as "verbal theories", but another part of the answer to Granovetter, which lies in the theorems of graph theory, is harder to discern. A survey of some of the material published since Granovetter posed his question yields disappointing results. The concepts of graph theory appear abundantly, 
though they are sometimes named idiosyncratically. Indices defined in terms of these concepts are constructed and their values for sets of empirical data are calculated and compared. These procedures are frequently rewarding and enhance our understanding of the real world. In many of these instances graph theory is clearly the most convenient, and sometimes the only available, source of analytic tools. A good example of analysis at this level is provided by Garbett (1980) who makes use of centrality measures and what he calls "graphs of inclusion" to elucidate the structure of an Indian caste hierarchy.

On the other hand, relations between graph theoretic concepts, as embodied in theorems, are seldom seen in network analysis. They do appear sometimes in discussions of analytic methods but are linked only rarely to real data sets. Yet as long as network analysts use only the concepts and terminology of graph theory while ignoring its theorems they are open to the charge made by Boissevain (1979: 393): they use dynamite to kill flies. The dynamic power of graph theory lies not in its terminology but, like any other branch of mathematics, in its theorems.

Graph theory uses two primitive, undefined terms, point and line; these two terms are mentioned in a small number of axioms, unproved statements assumed to be true. The primitive terms and the axioms together constitute the axiom system of graph theory. Its theorems consist of statements each of which can be derived logically either directly from the axiom system or indirectly by making use of theorems that have already been proved. Thus a theorem is tautologically true; it tells us nothing about the real world. Yet once it has been discovered it can be used with reference to any appropriate mathematical model of the real world that has bcen constructed with material from its axiom system. It then reveals real world implications of the model that might otherwise have not been noticed or utilized by the designer of the model (Harary et al. 1965: 3-4, 24-25).

Among the few papers published recently that use theorems we note Seidman and Foster's (1978) discussion of how Menger's theorem might facilitate an analysis of generalized cliques. Capobianco and Molluzzo (1980) use theorems about forests to simplify their proof of a new theorem about organizational trees and apply their findings to imaginary data. By proving and then using a theorem about the balance of the signed graph of a marked graph, an algorithm has been constructed for determining whether or not a given signed graph is bal- 
anced (Beineke and Harary 1978; Harary and Kabell 1980), an algorithm with obvious applications to real data. Maybee (1981) has applied somewhat similar notions to test the "sign stability" of causation matrices occurring in mathematical economics.

A theory worth its salt should not only provide retrospective explanation; it should also generate testable propositions and predictions. Predictions put to the test are, alas, even rarer occurrences in the literature of network analysis than are theorems put to use. A good example of hypothesis testing, though apparently carried out retrospectively rather than prospectively, is Zachary's (1975) study of a karate club. By using a capacitated network model and utilizing several theorems, he is able to provide a sociologically convincing account of how the club split into two. The alignment of club members in the two factions conforms to the model in 97 percent of cases.

In the subtitle of the journal Social Networks the term 'structural analysis' appears as if it were a synonym for 'network analysis'. The varieties of 'structuralism' are legion; adding yet another meaning to an all-too-fashionable word makes for confusion rather than clarity. Yet the use of 'structural' in this context is regrettably appropriate inasmuch as the great majority of examples of network analysis share with most other structural analyses the quality of being entirely static. Group dynamics may have been one of the antecedents of network analysis, but the dynamic characteristics of the former (clusive though they sometimes were) have been transformed into a static structuralism. An encouraging exception to this generalization is Doreian's work on structural change (1980), applying analytic tools of Atkin (1977) to field data collected by Davis and others (1941).

So far we have discussed the limited use network analysts have made of established theorems in graph theory. Seidman and Foster (1978:70) make the important point that the intellectual stimuli should flow in both directions. The problems encountered in the analysis of network data should stimulate what they call 'the development of anthropologically-motivated mathematics'. The example of factor analysis, a statistical technique developed to meet the needs of experimental psychologists (Eysenck 1953: 38-52), shows that mathematical invention and discovery is sometimes stimulated by social science. Maybe network analysts will also be successful in stimulating mathematicians to meet their special needs, or will manage to do the job elegantly themselves. Freeman's work on centrality (1979; Freeman et al. 1980) can be seen 
in this light. The example given from psychology shows also how the growth of a social science can be distorted when its practitioners become dominated not by empirical evidence but by a mathematical technique in which they assume a proprietary interest. Network analysts should be forewarned against this hazard.

Few network analysts nowadays would query Seidman and Foster's (1981) comment that "it is useful to regard a social network as a graph, thus gaining access to the precise terminology of graph theory". Regrettably, for many analysts, though not for these two authors, this is apparently all that graph theory has to offer. Empirical or imagined data are coded into graph theoretic categories, are fed into computers making use of specially written programmes, and generate useful results that in practice could not have been obtained in any other way. But it seems to us as if network analysts are all too often still at the stage of children learning the concepts of arithmetic by playing with Cuisinier rods; mathematics proper still lies ahead. Even in 1981 it may be true, as Lévi-Strauss (1954:583) asserted nearly thirty years ago, that "the confidence now shown by so many social scientists in mathematical models is due not so much to the results they themselves have secured by those methods as to the enormous assistance that mathematics has provided in other fields, and particularly physics". Nevertheless, by realizing what a short distance we have advanced, we may perhaps be enabled to move ahead faster.

\section{References}

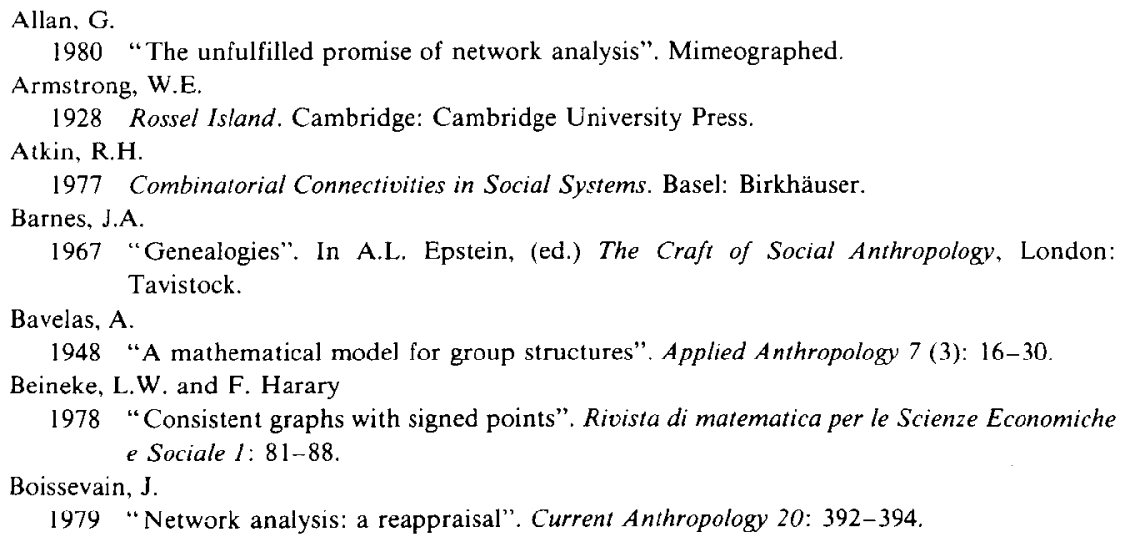


Bott, E.

1971 Family and Social Network (2nd cdition) London: Tavistock.

Capobianco, M.F. and J.C. Molluzzo

1980 "The strength of a graph and its application to organizational structure". Social Networks 2: 275-283.

Cartwright, D.

1953 "Preface". In F. Harary and R.Z. Norman, Graph theory as a mathematical model in social science. Ann Arbor: University of Michigan, Institute for Social Research. iii-v.

Cayley, A

1857 "On the theory of the analytical forms called trees". Philosophical Magazine 13: 19-30.

Chapple, E.D

1940 "Measuring human relations: an introduction to the study of the interaction of individuals". Genetic Psychologv Monographs 22 (1): 3-147.

Chapple, E.D. and C.S. Coon

1942 Principles of anthropology. New York: Holt

Davis, A., B. Gardner and M.R. Gardner

1941 Deep South. Chicago: Chicago University Press.

Doreian, $\mathrm{P}$.

1980 "On the evolution of group and network structure". Social Nctworks 2: 235252.

Euler, L.

1736 "Solutio problematis ad geometriam situs pertinentis". Commentarii Academiae Scientiarum Imperialis Petropolitanae 8: 128-140.

Eysenck, H.J.

1970 The Structure of Human Personality. London: Methuen.

Flament, $C$.

1963 "Applications of Graph Theory to Group Structure. Englewood Cliffs, NJ: PIcnlicie-Hall.

Freeman, L.C.

1979 "Centrality in social networks: conceptual clarification". Social Netw'orks 1: 215-239.

Freeman, L.C. et al.

1980 "Centrality in social networks: II. Experimental results". Social Networks 2: 119-141.

Garbett, G.K.

1980 "Graph theory and the analysis of multiplex and manifold relationships". In J.C.

Mitchell (ed.) Numerical Techniques in Social Anthropologv, Phıladelphia: Institute for the Study of Human Issues.

Granovetter, $M$.

1979 "The theory-gap in social network analysis". In P.W. Holland and S. Leinhardt, (eds.) Perspectives on Social Networks Research. New York: Academic.

Hage, $P$.

1978 "Speculations on Puluwatese mnemonic structure". Oceania 49: 81-95.

Harary, F.

1969 Graph Theory. Reading: Addison-Wesley.

1973 "On the history of the theory of graphs". In F. Harary, (ed.) New Directions in the Theory of Graphs, New York: Academic.

Harary, F. and J.A. KabelI

1980 "A simple algorithm to detect balance in signed graphs". Mathematical Social Sciences I: $131-136$.

Harary, F. and R.Z. Norman

1953 Graph Theory as a Mathematical Model in Social Science. Ann Arbor: University of Michigan, Institute for Social Research.

Harary, F., R.Z. Norman and D. Cartwright 1965 Structural Models. New York: Wiley. 
Harwood, F.

1976 "Mylh, memory, and the oral tradition: Cicero in the Trobriands". American anthropologist 78: 783-796.

Heider, F.

1946 "Attitudes and cognitive organization". Journal of Psychologv 2I: 107-122.

1979 "On balance and attribution". In P.W. Holland and S. Leinhardt (eds.) Perspectives on Social Network Research. New York: Academic.

Hull, C.L. et al.

1940 A Mathematico-deductive Theory of Rote Learning. New Haven, NJ: Yale University Press.

Kirchhoff, G.

1847 "Über die Ausflösung der Glcichungen, auf welche man bei der Untersuchung der linearen Verteilung galvanischer Ströme geführt wird". Annalen der Physik und Chemie 72: 497-508.

König, D.

1936 Theorie der endlichen und unendlichen Graphen. Leipzig: Akademische Verlagsgesellschaft.

Layard, J.

1942 Stone Men of Malekula. London: Chat to and Windus.

Leinhardt, S. (ed.)

1977 Social Networks. New York: Academic.

Lévi-Strauss, $C$.

1945 "L'analyse structurale en linguistique et en anthropologie". Word 1: 33-53.

1953 "Results of the conference from the point of view of anthropology". In C. Levi-Strauss et al. Results of the Conference of Anthropologists and Linguists. Baltimore: Indiana University, Waverly Press.

1954 "The mathematics of man". International Social Science Bulletin 6: 581-590.

1963 Structural Anthropology. New York: Basic Books.

Lewin, $\mathbf{K}$.

1936 Principles of Topological Psychology. New York: McGraw Hill.

Maybee, J.S.

1981 "Sign Solvability". In H.S. Greenberg and J.S. Maybee (eds.) Computer-assisted Analysis and Model Simplification. New York: Academic.

Mayer, A.C.

1966 "The significance of quasi-groups in the study of complex societies". In M. Banton (ed.) The Social Anthropology of Complex Societies. London: Tavistock.

Mitchell, J.C

1969 "The concept and use of social networks". In J.C. Mitchell (ed.) Social Networks in Urban Situations. Manchester: Manchester University Press.

Moreno, J.L.

1934 Who shall survive? Washington, DC: Nervous and Mental Disease Publishing Company.

Morgan, L.H.

1870 Systems of Consanginuity and Affinity of the Human Family. Washington, DC: Smithsonian Institution.

Radcliffe-Brown, A.R.

1940 "On social structure". Journal of the Royal Anthropological Institute $70: 1-12$.

Roethlisberger, F.J. and W.J. Dickson

1939 Management and the Worker, Cambridge, Mass.: Harvard University Press.

Seidman, S.B. and B.L. Foster

1978 "A note on the potential for genuine cross-fertilization between anthropology and mathematics". Social Networks 1: 65-72. 
1981 "An anthropological framework for the analysis of social networks". Mimeographed. Spinoza, B.

1977 Opera postuma. Amsterdam: Rieuwertz.

Warner, W.L. and P.S. Lunt

1941 The Social Life of a Modern Community. New Haven, NJ: Yale University Press.

Weil, A.

1949 "Sur l'étude algébrique de certains types de lois de mariage (Système Murngin)". In C. Lévi-Strauss, Less structures élémentaires de la parenté. Paris: Presses Universitaires de France.

White, H.C.

1963 An Anatomy of Kinship. Englewood Cliffs, NJ: Prentice-Hall.

Whitten, N.E., Jr. and A.W. Wolfe

1973 "Network analysis". In J.J. Honigmann (ed.) Handbook of Social and Cultural Anthropology. Chicago: Rand McNally.

Yates, F.A.

1966 The Art of Memory. London: Routledge and Kegan Paul.

Zachary, W.W.

1975 "The cybernetics of conflict in a small group: an information-flow model". M.A. thesis, Department of Anthropology, College of Liberal Arts. Temple University, Philadelphia. 